[3] Cantini F, Niccoli L, Nannini C. Second-line biologic therapy optimization in rheumatoid arthritis, psoriatic arthritis, and ankylosing spondylitis. Semin Arthritis Rheum. 2017;47(2):183-92.

Disclosure of Interests: None declared

DOI: 10.1136/annrheumdis-2020-eular.6508

\section{AB0318 $\quad$ CHARACTERISTICS OF PATIENTS WITH RHEUMATOID ARTHRITIS WHO HAVE WITHDRAWN THE LAST BIOLOGICAL DRUG: REAL-LIFE RESULTS FROM A LOCAL REGISTRY}

J. Rosas $^{1}$, A. Pons ${ }^{1}$, J. M. Senabre Gallego ${ }^{2}$, G. Santos Soler ${ }^{3}$, J. A. Bernal ${ }^{4}$, J. A. García-Gómez ${ }^{5}$, C. Cano ${ }^{4}$, E. Ivars ${ }^{4}$, M. Lorente Betoret ${ }^{6}$, X. Barber on behalf of AIRE-MB Group. ${ }^{1}$ Hospital Marina Baixa, Rheumatology, Villajoyosa (Alicante), Spain; ${ }^{1}$ Hospital Marina Baixa, Rheumatology, Villajoyosa (Alicante), Spain; ${ }^{3}$ Hospital Marina Baixa, Villajoyosa (Alicante), Spain; ${ }^{1}$ Hospital Marina Baixa, Rheumatology, Villajoyosa (Alicante), Spain; ${ }^{5}$ Hospital General Universitario de Elche, Infectious Disease, Elche, Spain; ${ }^{6}$ Hospital Marina Baixa, Rheumatology, La Vila Joiosa, Spain; ${ }^{7}$ Universidad Miguel Hernández de Elche, CIO, Elche (Alicante), Spain

Objectives: To assess the characteristics of patients with rheumatoid arthritis (RA), who have withdrawn the last biological drug (bDMARD), and to know the reasons for withdrawal of treatment.

Methods: Retrospective and cross-sectional study on December 31, 2019, of patients with RA, treated with any of the bDMARDs, including JAK (JAKi) inhibitor drugs, commonly used, from 1/1/2000 to 12/31/2019. General data were collected from patients, and RA: time of evolution, presence of rheumatoid factor (RF) and anti-citrullinated peptide antibodies (ACPA), type of bDMARD, time in bDMARD, and cause of withdrawal.

Results: Of 252 patients, who have received some bDMARD, 81 (32\%) patients had withdrawn on 12/31/2019. 62 (77\%) patients were women, with a mean age at diagnosis of RA of 48 years (SD: 16.5 years) and 59.5 (15) years at the beginning of the first bDMARD (F1), with an average evolution of RA 10.2 (2.5) years. $68 \%$ and $74 \%$ of patients were positive for RF and ACPA, respectively.

In $64(79 \%)$ patients, bDMARD was withdrawn as second to fifth bDMARD received (F2 to F5): as F2: 37/81 (46\%) patients, F3: 14 (18\%), F4: 8 (10\%) and as F5: (6\%) patients.

When comparing the last bDMARD received, before the suspension as $\mathrm{F} 1$ vs F2-F5, $95 \%$ vs. $61 \%$ of patients ( $p<0.0001$ ), the drug was an anti-TNF (TNFi); Abatacept: 1 (1\%) vs 9 (14\%); Tocilizumab: 0\% vs 8 (12\%); Rituximab: $1(1 \%)$ vs $5(8 \%)$ and JAKi: $4(5 \%)$ vs $3(5 \%)$. The mean time in treatment with some bDMARD was 2.6 (SD: 3 ) years in the F1 group vs 1.7 (2) years in the F2-F5 group ( $p=0.034)$. Among the F3-F5 patients, $9(14 \%)$ patients had failed at 2 different previous therapeutic targets and $6(9 \%)$ at 3 targets.

No differences were detected between the F1 group vs F2-F5, regarding the causes of withdrawal of bDMARD: whether it had occurred due to 1) loss of efficacy (25/31\% patients vs $19 / 30 \%)$; 2) adverse events (31/38\% vs. $29 / 45 \%$ ): infection: 18/81 (22\%) patients, malignancy: 5 (6\%), malaise/pain: $11(14 \%)$, laboratory parameters alteration: $7(9 \%)$, death: $5(6 \%)$, others: $14(17 \%)$; 3$)$ change of address/loss of follow-up ( $20 / 25 \%$ vs. $7 / 11 \%)$ or by 4$)$ voluntary abandonment of treatment by the patient $(5 / 6 \%$ vs. $9 / 14 \%)$.

Conclusion: $1.32 \%$ of patients with RA withdraw the bDMARD. 2. The group treated with TNFi withdraws it significantly higher among the F1 group. 3. Survival of bDMARD is significantly higher in group F1 compared to F2-F5. 4. No differences were detected between the groups regarding the cause of withdrawal of bDMARD. $25 \%-30 \%$ of patients withdraw it due to loss of follow-up or voluntary abandonment of bDMARD.

Acknowledgments: The study was supported by a research grant from the Association for Research in Rheumatology of the Marina Baixa (AIRE-MB).

Disclosure of Interests: None declared

DOI: 10.1136/annrheumdis-2020-eular.4824

\section{$\mathrm{AB} 0319$ \\ DRUG SURVIVAL OF BIOLOGICS IN RHEUMATOID ARTHRITIS: PRELIMINARY DATA FROM THE TUNISIAN BINAR REGISTRY}

K. Ben Abdelghani ${ }^{1}$, L. Rouached ${ }^{1}$, A. Fazaa ${ }^{1}$, S. Miladi ${ }^{1}$, K. Ouenniche ${ }^{1}$, L. Souabni ${ }^{1}$, S. Kassab ${ }^{1}$, S. Chekili ${ }^{1}$, L. Abdelmoula ${ }^{2}$, S. Baklouti ${ }^{3}$, N. Bergaoui ${ }^{4}$, E. Bouajina ${ }^{5}$, M. Elleuch ${ }^{6}$, I. Gharsallah ${ }^{7}$, Y. Mohamed ${ }^{8}$, M. M. Kchir ${ }^{9}$, S. Kochbati ${ }^{10}$, A. Laatar ${ }^{1} .{ }^{1}$ Mongi Slim Hospital, Rheumatology, La Marsa, Tunisia; ${ }^{2}$ Charles Nicolle Hospital, Rheumatology, Tunis, Tunisia; ${ }^{3} \mathrm{Hedi}$ Chaker Hospital, Rheumatology, Sfax, Tunisia; ${ }^{4}$ Hopital Fattouma Bourguiba, Rheumatology, Monastir, Tunisia; ${ }^{5}$ Farhat Hached hospital, Rheumatology, wو، Tunisia; ${ }^{6}$ La Rabta hospital, Rheumatology, Tunis, Tunisia; ${ }^{7}$ The military hospital in Tunis, Rheumatology, Tunis, Tunisia; ${ }^{8}$ Hospital University Tahar Sfar,
Rheumatology, Mahdia, Tunisia; ${ }^{9}$ kassab institute, Rheumatology, Manouba, Tunisia; ${ }^{10}$ Hôpital Habib Thameur, Rheumatology, Tunis, Tunisia

Background: The arrival of Biotherapy has changed the management and prognosis of rheumatoid arthritis (RA). However, drug survival of the first biotherapy is changing according to the studies.

Objectives: We aimed to report the data on the drug survival of biotherapies in RA, collected from the Tunisian Blologics National Registry (BINAR)

Methods: BINAR is a multicenter non-interventional and prospective study, conducted in Tunisia with 80 rheumatologists over a period of three years. It included patients with RA (ACR / EULAR 2010 criteria) and refractory to conventional background treatments (csDMARDs), who required the use of biological treatment of anti TNF, anti IL6 or Rituximab type. Data were collected and analyzed through an electronic platform managed by DACIMA. Sociodemographic data (age, gender, body mass index (BMI), smoking) and characteristics of RA (duration of evolution, erosive character) were collected. RA activity was studied by the DAS28-VS score and drug survival was evaluated by the duration of the biologics.

Results: We included 175 patients with a sex ratio of 5.7 and a mean age of $54.1 \pm 12.6$ years [19-79]. Patients were smoking in $6.7 \%$ of cases and mean BMI was $27.9 \pm 5.2 \mathrm{~kg} / \mathrm{m}^{2}$ [15.1-45.2]. RA was erosive in $73.1 \%$ of cases and the mean disease duration was $6.7 \pm 3.5$ years. Disease activity was moderate (mean DAS28vs: $4.9 \pm 1.5)$. Concerning the treatments, $139(79.4 \%)$ of the patients received TNFa inhibitor, $31(17.7 \%)$ of the patients were on IL6 inhibitor and 15 (8.6\%) were on Rituximab.

The mean duration of drug survival for TNFa inhibitor agents was 15.2 months, 18 months for anti IL6 and 16.3 months for Rituximab. The drug was discontinued by 19 patients (10.8\%). The causes of discontinuation were primary failure in $31.8 \%$ ( 7 subjects), secondary escape in $9.1 \%$ (4 subjects), the occurrence of adverse effects in $31.8 \%$ ( 7 subjects), intolerance to drug in $9.1 \%$ ( 2 subjects), non-compliance for one patient and for other reasons in one case.

The drug survival of TNF inhibitor was not associated with socio-demographic data (gender $(p=0.9)$, age $(p=0.4)$, smoking $(p=0.9)$, BMl $(p=0.9))$, nor with the characteristics of the disease duration $(p=0.5)$, DAS28 vs $(p=0.9)$, association with a csDMARDs $(p=0.2))$ except the presence of erosion $(p=0.013)$

Also, drug survival of IL6 inhibitor drugs was not associated with socio-demographic parameters (gender $(p=0.1)$, age $(p=0.6)$, smoking $(p=0.6)$, BMI $(p=$ $0.4)$ ) and the characteristics of the disease (duration $(p=0.9)$, erosive character $(p=0.6)$, DASvs $(p=0.1)$, association with a csDMARDs $(p=0.2)$ ).

Similarly, drug survival of Rituximab was not associated with socio-demographic data (gender $(p=0.6)$, age $(p=0.7)$, BMI $(p=0.7))$ or with the characteristics of RA (duration of evolution $(p=0.5)$, erosive character $(p=0.6)$, DASvs $(p=0.08)$, association with a csDMARDs $(p=0.5)$ )

Conclusion: Our study demonstrated that IL6 inhibitor had the longest duration of drug survival (18 months). The major causes of cessation were dominated by primary failure and the occurrence of an adverse event. Finally, the drug survival of TNF inhibitor agents was associated with the erosive character

Acknowledgments: none

Disclosure of Interests: None declared

DOI: 10.1136/annrheumdis-2020-eular.5935

\section{AB0320 1 BDMARDS SURVIVAL: THE TUNISIAN DATA}

K. Saadaoui ${ }^{1}$, H. Sahli ${ }^{1}$, S. Boussaid ${ }^{1}$, S. Jemmali ${ }^{1}$, S. Rekik ${ }^{1}$, E. Cheour ${ }^{1}$, M. Elleuch'. ' 'La Rabta Hospital, Rheumatology, Tunis, Tunisia

Background: The advent of biotherapies in the late 90 s radically changed the face of inflammatory diseases including rheumatoid arthritis. The survival of these innovative therapies is an indicator, in clinical practice, of their long-term efficacy and safety.

Objectives: The objective of this study was to assess their use in Tunisia through their survival during rheumatoid arthritis as well as to determine the factors that may influence their therapeutic maintenance in real life.

Methods: This is a retrospective study including RA patients (ACR/EULAR 2010 criteria) and putted on biotherapy between 01-01-2014 and 12-31-2016 They were followed until 12-31-2018. The therapeutic maintenance rate at $12,24,36$ and 48 months as well as the survival curves of biotherapies were analyzed using the Kaplan-Meier survival curves and compared by the Log-rank test. Reasons for interruption and patterns of biological change have been reported. Finally, an analysis of factors influencing survival was performed using Cox regression. A $\mathrm{p}<0.05$ was considered statistically significant.

Results: Three hundred seventy-four patients were included in the study; sex ratio was 0,147 . The baseline age was $55 \pm 12.5$ years [ $20-90]$ and the average disease duration was $11.7 \pm 6.7$ years [2 -41$]$. Rheumatoid factor and ACPA were positive respectively in $79 \%$ and $71 \%$ cases. After failure of cDMARD, the first biotherapy prescribed was etanercept in $54 \%$ 
of cases, adalimumab in $14 \%$ of cases, certolizumab pegol $13 \%$, infliximab $6 \%$, tocilizumab $6 \%$ and rituximab in $7 \%$ of cases, with an average DAS28 at baseline $6.01 \pm 0.89[5,37-6,50]$. Association with methotrexate was observed in $59,6 \%$ case and with corticosteroid in $57.2 \%$ case. Drug persistency rate at 12 months was $85.8 \%$; at 24 months, $69.9 \%$; at 36 months, $60.6 \%$ and at 48 months, $55.9 \%$. Survival was on average 41.7 months with $95 \% \mathrm{Cl}(39.47$ - 43.91). The presence of rheumatoid factors, the co-prescription of methotrexate as well as good initial therapeutic response were predictor of a better survival of biologicals at a statistically significant level $p<0.01$ (Hazard Ratios for pursuit of biotherapy were respectively $1.79,1.91$ and 2,3 ). The use of glucocorticoids was a negative predictor of retention (Hazard Ratio for therapy pursuit was 0.47 $p<0.001)$. This first biotherapy was stopped in $39 \%$ of cases and ineffectiveness was the major reason of interruption $(52.7 \%)$. The anti-TNFa cycling was the most adopted therapeutic strategy with $64.6 \%$ of cases. The survival rates of the second biotherapy at 12, 24 and 36 months were $91 \%, 76.4 \%$ and $72.1 \%$, respectively.

Conclusion: Our study provides information about biotherapy prescription practices in Tunisia and their effectiveness in "real life". It informs us about the use of these new therapies in our country and has shown an efficacy and a tolerance profile close to those reported in international registers.

Disclosure of Interests: None declared

DOI: 10.1136/annrheumdis-2020-eular.6498

\section{\begin{tabular}{l|l} 
AB0321 & EFFECT ON RETENTION RATES OF A NOVEL
\end{tabular} AUTOINJECTOR E-DEVICE IMPLEMENTED IN CLINICAL PRACTICE IN PATIENTS WITH CHRONIC ARTHRITIS TREATED WITH CERTOLIZUMAB PEGOL; A MULTI-CENTRE STUDY}

T. Schiødt Jørgensen ${ }^{1}$, R. L. Hansen ${ }^{1}$, B. Pouls ${ }^{2,3}$, B. Van den Bemt ${ }^{2,3}$ C. Sjowall ${ }^{4}$, L. E. Kristensen ${ }^{1} .^{1}$ The Parker Institute, Copenhagen University Hospital, Bispebjerg and Frederiksberg, Copenhagen F, Denmark; ${ }^{2}$ Sint Maartensliniek, Nijmegen, Netherlands; ${ }^{3}$ Radboud University Medical Center, Nijmegen, Netherlands; ${ }^{4}$ Linköping University, Department of Biomedical \& Clinical Sciences, Linköping, Sweden

Background: Anti-tumour necrosis factor (anti-TNF) adherence is suboptimal and impacted by multiple psychological, practical and physical barriers, such as patient needle phobia, lack of confidence in self-administration skills and forgetting injection dates $(1,2)$. ava $\AA$, a reusable electro-mechanical self-injection device (e-Device) developed for certolizumab pegol (CZP) administration, aims to overcome some of these barriers.

Objectives: The objective of this study was to explore the clinical retention rate of an e-Device aimed at empowering chronic arthritis patients using CZP. Methods: Patients treated with CZP were recruited from the Netherlands, Denmark and Sweden through rheumatology clinics to evaluate patient experience with the e-Device. Patients were adults (aged between 18 and 85 years) with RA, axSpA or PsA. After being trained on how to use the e-Device, patients administered 3 consecutive self-injections on their own. Descriptive statistics for baseline characteristics, retention rates and reasons for withdrawal were assessed. Data on physical function (HAQ) are reported for Denmark and Sweden only due to lack of data from Holland.

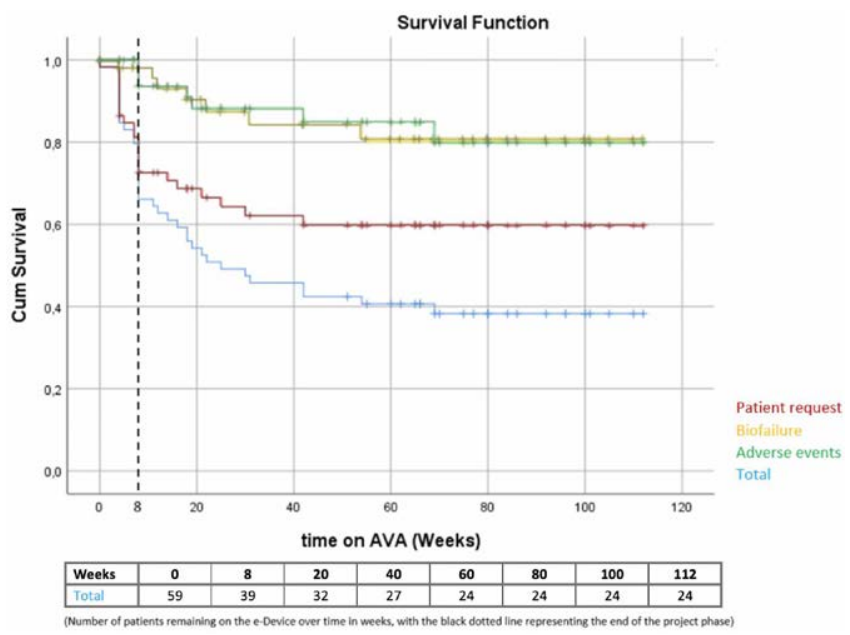

Figure 1. Overall retention rate and reasons for withdrawal
Results: 59 patients participated in the study (Netherlands: 25; Denmark 15; Sweden: 19). Most patients were women (71\%), with a mean age of 55 years [16.2] and an average disease duration of 12 years [8.8]. A total of $42 \%$ and $39 \%$ had previously been treated with csDMARD(s) or were currently on $\operatorname{csDMARD}(\mathrm{s})$, respectively. $12 \%$ of the patients were bio-naive. Only $6(10 \%)$ patients started CZP de novo. The remaining switched device. The most used administration form prior to entering the study was pre-filled syringe $(78 \%)$. At the time of inclusion, patients were mildly disabled with an average HAQ score of 0.5 [0.6] and a moderate VAS-pain score of 32 [25.1] (data not shown).

The overall retention rate was $42 \%$ after 52 weeks, declining to $38 \%$ after 104 weeks (Figure 1). A sharp decline is seen at week 8 which coincides with the end of the project phase. Between week 32 and 112 only 4 patients withdrew from the study (Figure 1). The primary reason for withdrawal was patient's request (Figure 1). Dropout rates due to lack of efficacy or adverse events were as expected compared to other cohorts of biologic therapies. When stratified by country the analysis showed no significant differences between countries (data not shown)

Conclusion: An initial large drop-out was evident within the first 8 weeks, whereas almost no drop-out was seen in the extension phase (after week 8). The reasons for withdrawal was primarily patient request. Thus, the injection experience must be tailored carefully when selecting patients for new autoinjector e-Devices to enhance retention on device and patient satisfaction. Not one device fits all.

\section{References:}

[1] Maniadakis N, Toth E, Schiff M, et al. A Targeted Literature Review Examining Biologic Therapy Compliance and Persistence in Chronic Inflammatory Diseases to Identify the Associated Unmet Needs, Driving Factors, and Consequences. Adv Ther 2018;35:1333-1335

[2] Lopez-Gonzalez R, Leon L, Loza E, et al. Adherence to biologic therapies and associated factors in rheumatoid arthritis, spondyloarthritis and psoriatic arthritis: a systematic literature review. Clin Exp Rheumatol 2015;33:559-69.

Acknowledgments: This study was funded by UCB

Disclosure of Interests: Tanja Schjødt Jørgensen Speakers bureau: Abbvie Pfizer, Roche, Novartis, UCB, Biogen, and Eli Lilly, Rebekka L. Hansen: None declared, Bart Pouls: None declared, Bart van den Bemt Grant/research support from: UCB, Pfizer and Abbvie, Consultant of: Delivered consultancy work for UCB, Novartis and Pfizer, Speakers bureau: Pfizer, AbbVie, UCB, Biogen and Sandoz., Christopher Sjowall: None declared, Lars Erik Kristensen Consultant of: UCB Pharma (Advisory Board), Sannofi (Advisory Board), Abbvie (Advisory Board), Biogen (Advisory Board), Speakers bureau: AbbVie, Amgen, Biogen, Bristol-Myers Squibb,Celgene, Eli Lilly, Gilead, Forward Pharma, Janssen Pharmaceuticals, MSD, Novartis, Pfizer, and UCB Pharma DOI: 10.1136/annrheumdis-2020-eular.2814

\section{$\mathrm{AB} 0322$ \\ LESSONS LEARNED FROM THE PAST THAT SHOULD IMPROVE THE FUTURE: 18 YEARS OF EXPERIENCE WITH BIOLOGIC THERAPIES IN RHEUMATOID ARTHRITIS IN A TERTIARY RHEUMATOLOGY CENTER IN ROMANIA}

T. Serban $^{1,2}$, I. Satulu ${ }^{3}$, I. Badea ${ }^{2}$, C. Mihai $^{2}$, D. Badea ${ }^{2}$, O. Vutcanu ${ }^{2}$, A. Martin $^{1,2}$, M. Milicescu ${ }^{1,2}$, G. Udrea ${ }^{1,2}$, M. Bojinca ${ }^{1,2}$. "Carol Davila" University of Medicine and Pharmacy, Bucharest, Romania; ${ }^{2}$ "Dr. I. Cantacuzino"Clinical Hospital, Bucharest, Romania; ${ }^{3} \mathrm{Kalmar}$ County Hospital, Kalmar, Sweden

Background: Rheumatoid arthritis (RA) is a chronic inflammatory disease, which affects approximately $1 \%$ of the population. Although diagnostic, monitoring and treatment strategies have improved noticeably over the last decades, allowing an early and sustained clinical and radiologica remission, both direct and indirect costs of treatment and disease still create an economic burden for patients and society. The last few years have brought many therapeutic options and knowledge about them, which has led to the 2019 updated EULAR recommendations for the management of RA (1).

Objectives: This study aimed to evaluate the trends in prescribing of biologic therapies in RA over time, the factors that influenced them and the persistence of patients on these treatments.

Methods: In this retrospective study we evaluated patients with RA treated with biologic therapies in the last 18 years, who presented for routine clinical and biological evaluation, performed according to the standard of care principles in RA.

Results: 244 patients were enrolled in this study. Baseline characteristics are presented in Table 1. 